\title{
A produção do currículo do final da vida por meio do dispositivo pedagógico da mídia
}

Franciele Roberta Cordeiro(a)

Maria Henriqueta Luce Kruse ${ }^{(b)}$

Cordeiro FR, Kruse MHL. Production of an end-of-life curriculum vitae through the pedagogical apparatus of the media. Interface (Botucatu). 2015; 19(55):1193-205.

This paper analyzed how the discourse on death circulates within the Brazilian media, thereby producing an endof-life curriculum vitae. It stemmed from document research in which the theoretical-methodological reference framework was the thinking of Michel Foucault. The empirical material was composed of ten reports that circulated in the magazines Época and Veja between 2002 and 2012. To delimit the corpus for the analysis, discursive mapping was elaborated using the ATLAS.ti 7 software. The findings were subjected to discourse analysis inspired by Foucault's thinking. The acceptance of death and its domestication appeared as strategies produced by the State and legitimized through the media. These informative Brazilian magazines produced end-oflife curricula vitae, thereby teaching and publicizing acceptance of death and calling on subjects to govern their own end. Those who escape from this discursive order are considered to be "abnormal" in the end-of-life context.

Keywords: Death. Nursing. Palliative care. Education nursing. Cultural Studies.
Neste artigo, que partiu de uma pesquisa documental cujo referencial teóricometodológico foi o pensamento de Michael Foucault, analisa-se como os discursos sobre a morte circulam na mídia brasileira, produzindo um currículo do final da vida. O material empírico foi composto de dez reportagens que circularam entre 2002 e 2012 nas revistas Época e Veja. Para delimitar o corpus de análise, elaborou-se um mapeamento discursivo com o software ATLAS.ti 7, e os achados foram submetidos à análise do discurso de inspiração foucaultiana. A aceitação da morte e sua domesticação despontam como estratégias produzidas pelo Estado e legitimadas pela mídia. As revistas informativas brasileiras produzem um currículo do final da vida, ensinando e propagando a aceitação da morte e convocando os sujeitos a governarem seu fim. Aqueles que escapam dessa ordem discursiva são considerados os "anormais" no contexto do final da vida.

Palavras-chave: Morte. Enfermagem. Mídia. Educação em Enfermagem. Estudos Culturais.

\footnotetext{
(a,b) Programa de Pós-Graduação em Enfermagem, Universidade Federal do Rio Grande do Sul. Rua São Manoel, 963, sala 205, Rio Branco. Porto Alegre, RS, Brasil. 90620-110. franciele.cordeiro@ ufrgs.br;
} 


\section{Sobre o que ensinar}

Um currículo é um caminho que mostra a direção na qual devemos seguir. Atua por meio de um processo educativo, modulando comportamentos, ou seja ${ }^{1}$, tem por finalidade constituir sujeitos, tendo sido considerado um instrumento de excelência para educar na modernidade. Esse dispositivo "conecta o que se passa no eixo do pensamento com o que se passa no eixo do corpo; entre as muitíssimas coisas que o currículo faz, está a relação que ele estabelece entre o que se pensa e o que se faz" ${ }^{1}$ (p. 7). Nesse aspecto das relações, entre aquilo que se pensa e aquilo que se faz, podemos configurar a mídia como dispositivo pedagógico.

A mídia é um importante meio de difusão de comportamentos, constitutiva de opiniões, modos de agir e pensar, 'ensinando' como se portar frente às diferentes demandas, inclusive, a respeito da morte ${ }^{2}$. O jornal, a televisão, a internet, o rádio e as revistas são os meios pelos quais a população tem acesso a informações sobre os mais variados temas. Dentre as notícias ou informações que circulam nesses meios, a morte aparece com frequência. Por meio da mídia, tomamos conhecimento daqueles que faleceram, do modo como faleceram e de que maneira isso impactou na organização social.

Uma das formas de abordar a morte na mídia é apresentá-la como questão ética a ser debatida. Sob a perspectiva foucaultiana, utilizada para desenvolver este estudo, os discursos que circulam na mídia constituem-se de enunciados que ganham legitimidade, atravessando os corpos que os 'consomem'. Assim, os bens produzidos pela mídia tornam-se lugar de produção de verdades e de circulação de ideias, valores, normas, posturas, propondo modos de conduzir tanto a vida quanto a morte dos sujeitos ${ }^{3}$.

Os sentidos atribuídos à morte em uma sociedade nos permitem conhecer o lugar que os corpos ocupam e como são atravessados por normas, valores e desejos, variando conforme a cultura e as demandas de cada sociedade. As experiências relacionadas ao final da vida passam pelo corpo e oscilam entre algo que é aceito e inevitável e aquilo do que é necessário afastar-se ${ }^{4}$. Conhecer a experiência sobre a morte em uma sociedade nos remete a pensar sobre o modo como os corpos são atravessados por normas, valores e desejos. Utilizamos a palavra experiência neste texto para caracterizar aquilo que nos passa e nos toca, "aquilo que acontece afeta de algum modo, produz afetos, inscreve algumas marcas, deixa alguns efeitos" ${ }^{5}$ (p. 24). Como exemplo de experiência, destacamos as diferentes concepções acerca de eventos que permeiam o morrer, como: a eutanásia, o suicídio assistido, os Cuidados Paliativos, entre outros que são concebidos de diferentes modos em alguns países. Na Inglaterra, é emergente o debate sobre o suicídio assistido. Na Holanda e na Suíça, instituições auxiliam pessoas a terminarem suas vidas, em caso de doenças fora de possibilidade de cura ${ }^{6}$. Na França, por exemplo, houve uma abertura, a partir de 2004, para as questões relativas ao governo da morte por parte dos sujeitos, por meio de Diretivas Antecipadas de Vontade, decorrente da repercussão midiática do caso de Vincent Humbert? Em 2012, o Conselho Federal de Medicina do Brasil aprovou as Diretivas Antecipadas de Vontade, que, semelhantes ao modelo francês, visam atender o desejo das pessoas que estão fora de possibilidade de cura, seja para prolongar ou encerrar a vida .

Ao operar com a morte e a mídia, questionamos: Como a mídia (re)produz e veicula discursos a respeito da morte? Quais são as condições que permitem sua circulação? Visando potencializar essas questões, este estudo tem como objetivo: analisar como discursos sobre a morte circulam na mídia brasileira, produzindo um currículo do final da vida.

\section{Das estratégias utilizadas}

Este artigo partiu de uma pesquisa documental, de abordagem qualitativa, inserida na vertente pós-estruturalista dos Estudos Culturais. Essa perspectiva teórica assume que a cultura interfere: na organização do mundo contemporâneo, nas relações estabelecidas entre os diferentes povos e, também, nos sistemas econômicos e políticos. Segundo essa perspectiva, a linguagem é um elemento que atravessa os sujeitos, partindo de relações de poder que não são únicas ou opressoras, mas que produzem efeitos nos modos como nos constituímos e conduzimos as questões relacionadas à saúde, à política, à doença, entre outras 9 . 
O material empírico da pesquisa constituiu-se de reportagens de revistas que abordavam a temática do final da vida. Foram recuperadas aquelas que discutiam a morte como um processo, cujos envolvidos tinham ciência de sua chegada iminente e tinham a chance de se preparar (ou não) para ela. A opção por trabalhar com revistas se deve à heterogeneidade do público que elas conseguem atingir. Os discursos foram capturados em duas revistas de importante circulação no Brasil: Veja, da editora Abril, e Época, da editora Globo. Em conjunto, as revistas têm uma tiragem semanal de cerca de um milhão e quinhentos mil exemplares. A recuperação dos discursos foi realizada nas bibliotecas virtuais das revistas e em edições impressas, entre dezembro de 2012 e janeiro de 2013.

Foram consultadas as reportagens que estavam na íntegra, a partir do ano 2000. Essa demarcação temporal se deve ao movimento observado acerca das decisões sobre o término da vida e dos cuidados a pacientes com doença fora de possibilidade de cura. No Brasil, verifica-se nesse período: a implantação de serviços de Cuidados Paliativos, a aprovação da Resolução no 1.996/12, que dispõe sobre a elaboração de Diretivas Antecipadas de Vontade do paciente (2012), a Política Nacional de Atenção Oncológica (2005), a Política Nacional de Atenção Domiciliar (2013) e a Política Nacional de Humanização (2004). Consideram-se tais eventos como superfícies de emergência para as transformações no cenário de cuidado à saúde. Ao término do levantamento, foram incluídas dez reportagens, quatro da revista Veja e seis da revista Época. O período das publicações variou entre 2002 e 2012, conforme descrito na Tabela $1^{10}$.

Tabela 1. Material empírico da pesquisa

\begin{tabular}{lllcl}
\hline Ano & Revista & \multicolumn{1}{c}{ Reportagem } & Páginas & Resgate \\
\hline 2002 & Veja & Até onde prolongar a vida. & $82-91$ & Acervo Digital \\
2005 & Veja & Em busca de um final sereno & $92-100$ & Acervo Digital \\
2008 & Época & A mulher que alimentava & $68-74$ & Online/Impressa \\
2008 & Época & A enfermaria entre a vida e a morte & $56-66$ & Online/Impressa \\
2010 & Veja & A ética na vida e na morte & $100-107$ & Acervo Digital \\
2010 & Época & Testamento Vital & - & Online \\
2010 & Época & O filho possível & $82-88$ & Online \\
2012 & Época & Ajuda-me a morrer & - & Online/Impressa \\
2012 & Época & Você quer ser pessoa ou paciente? & $98-106$ & Online \\
2012 & Veja & O direito de escolher & & Acervo Digital \\
\hline
\end{tabular}

Fonte: Cordeiro ${ }^{8}$.

Para a elaboração do mapeamento discursivo, primeiramente, foram utilizados quadros para organizar os discursos, nos quais foi possível resgatar os dados relativos a quem estava autorizado a falar, de onde falava, favorecendo as análises e a interação entre pesquisador e material empírico. Em seguida, foi utilizado o software de organização e análise de dados qualitativos ATLAS.ti 7 em sua versão Free Trial, disponibilizada gratuitamente para avaliação ${ }^{11}$.

Os achados da pesquisa foram submetidos à análise do discurso proposta por Michel Foucault, apoiada, sobretudo, nos conceitos desenvolvidos nas obras $A$ arqueologia do saber ${ }^{12}$ e $A$ ordem do discurso ${ }^{13}$. Para o autor, "analisar o discurso é fazer com que desapareçam e reapareçam as contradições; é mostrar o jogo que nele elas desempenham; é manifestar como ele pode exprimi-las, dar-Ihes corpo ou emprestar-Ihes uma fugidia aparência"12 (p. 171). A noção de discurso foi utilizada como ferramenta metodológica, e, a noção de governo, como grade analítica, a qual consubstanciou e articulou as discussões realizadas. 


\section{A construção do currículo do final da vida: modos de ensinar sobre a morte e o morrer}

Neste artigo, apresentamos a maneira como as revistas informativas brasileiras constroem um jeito de ensinar os leitores sobre as decisões a serem tomadas para viver o final da vida. Trata-se de parte dos dados de uma pesquisa que abordou a constituição de sujeitos que governam sua morte, a partir dos discursos midiáticos ${ }^{(c)}$.

Por meio das revistas, é possível 'aprender' a viver o final da vida, com uma doença fora de possibilidade de cura. Tais ensinamentos são apresentados, especialmente, pelas imagens e pelas descrições física e psicológica dos sujeitos em processo de morrer. As revistas podem ser consideradas como guias, os quais apontam os caminhos para planejar a 'boa morte': aquela em que o sujeito decide como morrer, de preferência, no domicílio. Ressaltamos que essa 'escolha' não é realizada de forma implícita, já que os leitores são impelidos a tomar decisões sobre sua morte a partir de discursos médicos, religiosos, jurídicos e outros apresentados pelas revistas.

Para produzir esse outro jeito de morrer, tanto a revista Veja quanto a revista Época põem os leitores em contato com aquilo que se quer tornar verdade. Os discursos das revistas utilizam a narrativa (que aproxima os sujeitos de situações já experimentadas por outros) do ensino sobre conceitos como eutanásia e cuidados paliativos, da aceitação da morte como um padrão de normalidade, e do domicílio como o local que produz a morte segura e sem sofrimento.

\section{Aprendendo com a experiência do outro}

Destacamos a narrativa midiática como uma potente estratégia de convencimento, utilizada, especialmente, pela revista Época. Em suas edições, contar a vida daqueles que morrem e apontar os aspectos para se alcançar a boa morte, a partir da experiência, comove, chama a atenção e cativa o leitor, que tem a possibilidade de aprender com o outro. Busca-se dar visibilidade às experiências de pessoas, geralmente de meia-idade, que passaram por situações que envolviam a morte e o morrer.

Existem diferenças entre os sujeitos que narram suas histórias nas revistas analisadas. Na Época, geralmente, falam as pessoas comuns: familiares, cuidadores, pessoas em processo de morrer. Na Veja, são ouvidos os médicos, que opinam sobre como gostariam de morrer e como acham que isso deve acontecer. Tal fato demonstra a importância das ciências médicas nos modos de viver/morrer. Os médicos se colocam na condição de terminalidade para narrar suas condutas nessa situação.

Ailce de Oliveira Souza não é uma filósofa, é uma merendeira de escola. [...]. Faz quase um ano que sua pele amarelara e ela se enchera de náuseas. ${ }^{14}$ (p. 69)

Eu pediria para não ser submetido a procedimentos que me privassem da qualidade de vida. Afinal, o conceito de qualidade de vida muda muito com a proximidade da morte. Outro ponto crucial: nenhum tratamento deverá comprometer as finanças da minha família (médico oncologista). ${ }^{15}$ (p. 103)

\author{
(c) Artigo elaborado a \\ partir da dissertação \\ de mestrado intitulada: \\ "Eu decido meu fim: a \\ mídia e a produção de \\ sujeitos que governam \\ sua morte", apresentada \\ pela primeira autora \\ deste artigo ao Programa \\ de Pós-Graduação \\ em Enfermagem da \\ Universidade Federal do \\ Rio Grande do Sul em \\ 2013.
}


A articulação entre a narração das histórias e os discursos das revistas configura comportamentos e práticas frente à morte. Observa-se que uma 'luz' aponta para os sujeitos no final da vida, partindo da possibilidade de a morte transcorrer 'naturalmente'.

Até meados dos anos 2000, percebia-se um grande investimento na vida; porém, desde então, vem evidenciando-se uma ruptura no modo de enfrentar o morrer. As revistas apontam essa mudança, articulando experiências individuais com as possibilidades oriundas das políticas públicas de saúde e da legislação brasileira. Mais do que informar, elas narram. Nesse sentido, a experiência ultrapassa a informação: ela passa pelas sensações, pela interpelação, pela descrição, pelo detalhe do vivido ${ }^{16}$.

A partir das narrativas, é possível promover o encontro entre os leitores e as histórias dos outros. É nessa aproximação, aparentemente virtual, que se dá o contato e a atuação pedagógica da mídia. Por meio do tencionamento das histórias, ela produz, inventa, faz circular e vende verdades que repudiam o investimento fútil nos corpos moribundos. Esse encontro utiliza, além das palavras, as imagens. Acreditamos que o visual, o colorido e a disposição das luzes articulados com as falas favorecem a constituição da experiência com a morte do outro no cenário midiático.

As figuras 1 e 2 nos mostram uma cena característica dos dias de hoje: a exposição da vida privada, que então se torna de domínio público. O self, que antes se narrava no diário tradicional, agora vai se constituindo como protagonista da vida, a partir do atravessamento do outro, possibilitado pelas tecnologias da informação, em que os meios de comunicação, como as revistas, encontram-se inseridos ${ }^{16}$.

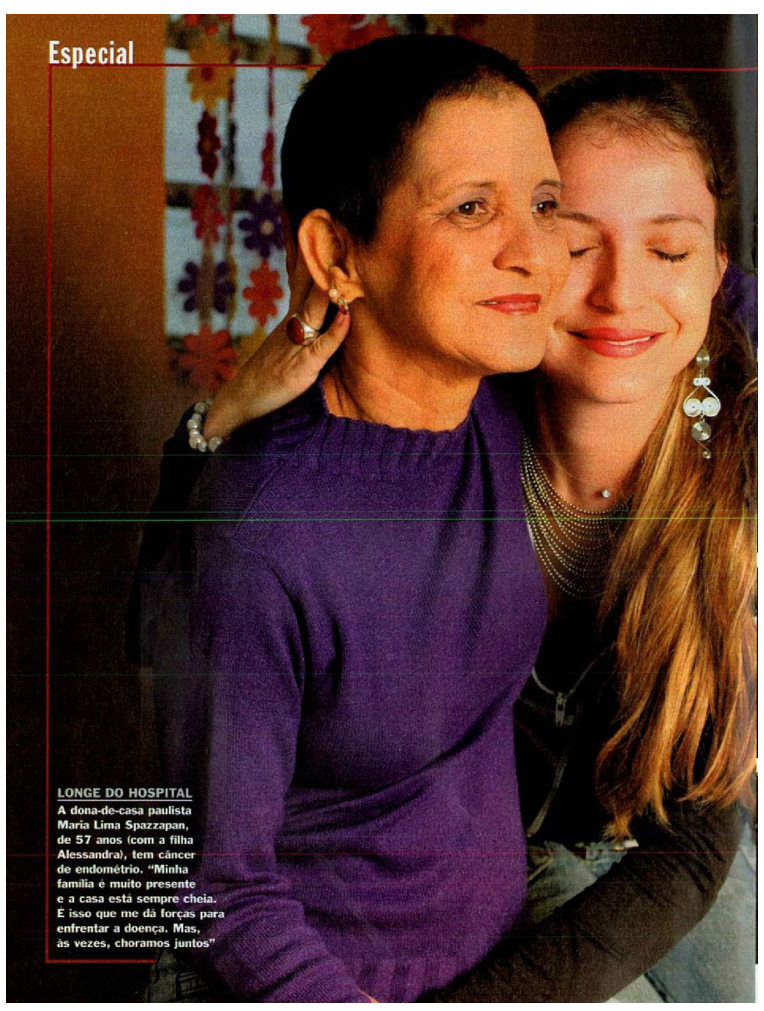

Figura 1. Longe do hospital

Fonte: Veja ${ }^{17}$. Créditos: Paulo Vitale

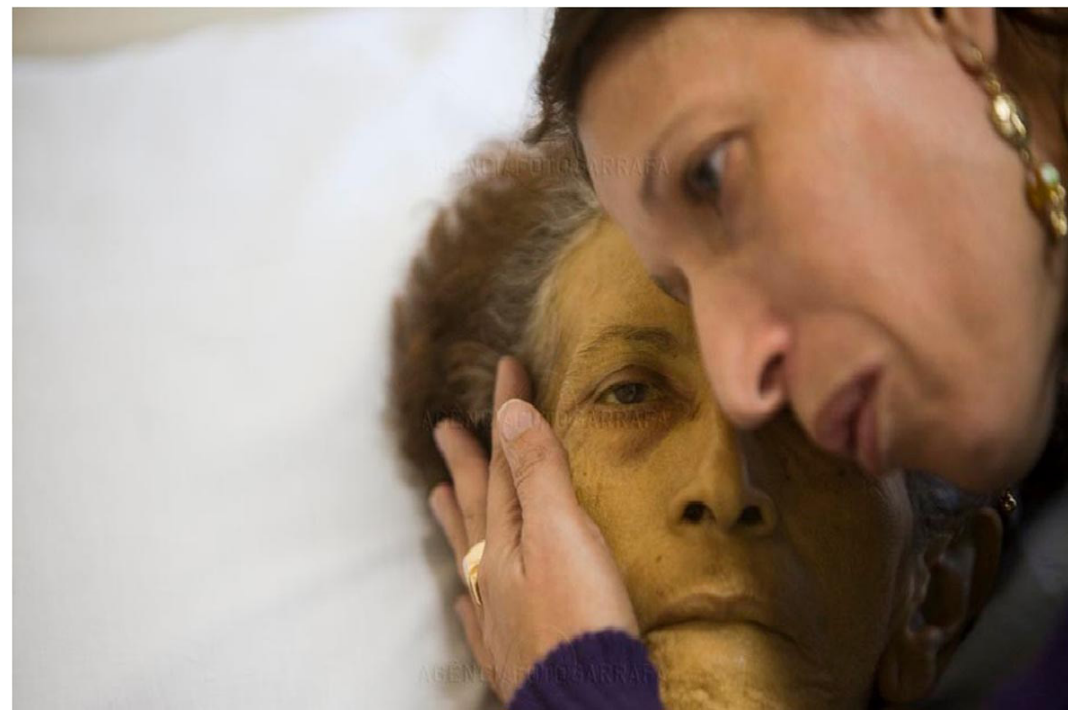

Figura 2. A mulher que alimentava

Fonte: Época ${ }^{14}$. Créditos: Marcelo Min 
Nas imagens divulgadas pelas revistas Veja e Época, a primeira do ano de 2005 e, a segunda, de 2008, respectivamente, vemos o retrato do processo de morrer no contemporâneo, transposto para o público que lê os artigos das revistas. Elas apresentam imagens de pessoas com doença fora de possibilidade de cura, chamando a atenção para a morte ocorrida sem a intervenção da tecnologia e fora do ambiente hospitalar. Tais pessoas são acompanhadas pela família em seus momentos finais, sendo retratadas e interrogadas para que, dessa forma, ensinem os outros, que aprenderão com suas experiências.

O hospital é citado como um local positivo, quando dispõe de uma unidade de Cuidados Paliativos, e é onde se encontra a senhora da Figura 2. Na Figura 1, observamos a nota no canto esquerdo, que diz: "Longe do hospital". Essa parece ser uma verdade que circula: a boa morte é aquela que ocorre no domicílio, longe do hospital. A outra seria a aceitação da morte, que se configura como norma.

Observamos, primeiramente, a tentativa de retirar dos hospitais, encaminhando para suas residências, aqueles que estão fora de possibilidades de cura, visando proporcionar a intimidade entre família e moribundo. Posteriormente, percebemos quanto tal evento é mostrado, por meio de fotografias de pessoas em processo de morrer, em blogs e nas redes sociais, como facebook e orkut. Entre os anos de 2011 e 2012, circularam pela internet imagens de pais que fotografavam as fases da vida de um filho com doença incurável até o momento da morte, de maridos com suas esposas etc. Observa-se uma exposição de eventos que, antes, eram escamoteados das discussões entre amigos, familiares e colegas. As pessoas são instigadas a se mostrarem, a se narrarem em textos breves, aquilo que Walter Benjamin denominou short story: pequenas histórias que nos contam, que nos passam e que, com a mesma velocidade, dissipam-se, acompanhando a temporalidade em que vivemos ${ }^{18}$.

Nos textos das revistas, apontamos o destaque dos sujeitos nas imagens que circulam concomitantes à divulgação do novo Código de Ética Médica, que autoriza a ortotanásia no cenário brasileiro. Nas figuras ( 1 e 2), o enunciado da individualização desponta no discurso de pessoas que decidiram não investir em tratamentos considerados fúteis, tendo em vista a impossibilidade de cura. A expressão dos envolvidos nas cenas indica que a morte nessa perspectiva é tranquila e confortável. O jogo de luzes transparece a leveza pela escolha correta: deixar-se morrer. Essas sensações não parecem ser experimentadas apenas pelas pessoas doentes, mas, também, pelas famílias, que, por meio do abraço, do toque, as abrigam.

Acreditamos que dar visibilidade às pessoas comuns e fazer circular a imagem da 'boa morte' são estratégias que a mídia utiliza para legitimar certas verdades. Ela funciona como um "local de superposição de verdades, justamente por ter se transformado em um local de produção, veiculação e circulação de enunciados de múltiplas fontes, sejam eles diretamente criados a partir de outras formações, ou a partir dos próprios meios"19 (p. 123). A mídia utiliza a narração, o testemunho, o relato da experiência dos outros como forma de enunciação que dá veridicidade àquilo que faz circular, pois aquele que enuncia parte de uma dada 'realidade' vivida e, por isso, Ihe é dada autoridade para falar. Assim, o sujeito que aparece nas reportagens é "levado a dizer o que viu, ouviu ou tocou, sem análise nem julgamento" 20 (p. 224), visando convencer os leitores sobre as verdades divulgadas pelas revistas.

\section{Esclarecendo sujeitos para produzir verdades}

As duas verdades que circulam, a 'boa morte', como aquela que ocorre no domicílio, e a aceitação da morte, configuram-se como norma. Elas são reforçadas pelos modos como as revistas esclarecem os sujeitos a respeito dos conceitos que envolvem o final da vida. Esclarecem e mostram por que devemos morrer, deixando que as doenças sigam seu curso 'natural'. Essa função, tanto esclarecedora como direcionadora, faz da mídia uma instituição formadora de opinião, não sendo a 'vilã', muito menos a 'mocinha', quando seleciona e faz circular determinadas verdades. "Os sentidos são compreendidos de acordo com as possibilidades existentes. E esta aparente diluição - de sentidos, de imposições, de poderes - é certamente uma das estratégias de sobrevivência, manutenção e atualização das mídias" 21 (p. 128). 
Os procedimentos incluídos nessa nova forma de tratar os doentes terminais levam o nome genérico de cuidados paliativos. ${ }^{22}$ (p. 106)

Nem antecipar a morte nem esticar a vida, mas garantir que se viva até o fim com dignidade (sobre os cuidados paliativos). ${ }^{14}$ (p. 58)

Aponta-se o papel das revistas como tradutoras dos conceitos científicos para a população. Ao utilizar o termo tradução, não acreditamos que a mídia, simplesmente, apresenta de outra forma os discursos. Ela os modifica e, também, atribui outros sentidos para aquilo que põe em voga e esclarece, visto que todo discurso que circula carrega consigo uma intencionalidade, a fim de participar dos jogos de poder em torno das relações midiáticas.

Aqui, o termo tradução é utilizado segundo a perspectiva de Foucault na obra Arqueologia do saber. A tradução dos termos que envolvem a morte atua como um procedimento de intervenção na formação de conceitos, a partir de determinados enunciados. Em outras palavras, para pôr em funcionamento certas práticas, é necessário que se facilite o acesso dos sujeitos àquilo que se quer difundir, por meio de técnicas de: reescrita, transcrição, tradução, aproximação, delimitação de um campo e sistematização de elementos que, juntos, colocam em evidência aquilo que se quer tornar visível. Por meio do esclarecimento, as revistas tanto ensinam sobre aspectos conceituais do final da vida como apresentam os dilemas éticos e legais. Os enunciados contidos nos discursos precisam ser ditos de outra forma, apresentados por meios que favoreçam suas disposições e assegurem a difusão da boa morte e a introjeção desta pelos sujeitos. Por meio dessa disposição, a mídia vai operando um dispositivo pedagógico que ensina, significa, posiciona e educa as pessoas segundo as direções que ela aponta $^{16}$.

Contemporaneamente, presenciamos a globalização nos modos de ensinar. Aprendemos por meio da escola, das revistas, da televisão, da propaganda, sendo atravessados pelos inúmeros discursos que pretendem nos constituir como sujeitos ${ }^{10}$. Nos são apresentados diferentes currículos, que produzem significados, partindo de diferentes espaços de cultura e do encontro com diferentes instituições, dentre elas a mídia ${ }^{16}$. O currículo que a mídia elabora vai pontuando as práticas em torno da morte, para as quais se quer dar visibilidade e as quais se quer tornar verdade. Nos discursos, verifica-se a instauração da normalidade em relação à aceitação do fim. Ensina-se que as pessoas devem encarar a morte, aceitá-la como algo inevitável e participar das decisões tomadas a respeito, até quando possível.

Quem teve uma vida feliz, na qual conseguiu boa parte dos objetivos da juventude, também tende a encarar a morte com tranquilidade $[\ldots] .{ }^{17}$ (p. 98)

Na Enfermaria (dos Cuidados Paliativos do Hospital do Servidor Público de São Paulo) não há espaço para frases como: "Me entrego em suas mãos, doutor". Como viver a morte é uma decisão do paciente, é ele o responsável por sua vida até o fim - ou sua família, se já não puder decidir. ${ }^{14}$ (p. 72)

Uma norma se configura a partir da regularidade de certos comportamentos e ações passíveis de observação ${ }^{23}$. Pela observação das condições favoráveis, sejam elas políticas, econômicas, sociais ou culturais, podem ser inventados padrões de normalidade que capturam os sujeitos em uma trama de relações, visando ao seu enquadramento dentro da norma vigente.

A partir dos anos 2000, constitui-se um processo de normalização em torno do final da vida que, por meio da aceitação, visa inserir os sujeitos na ordem desse discurso. Tal processo é circunscrito por elementos históricos que possibilitam a emergência da aceitação da morte. Destacamos: a atualização do Código de Ética Médica (2010), especialmente a Resolução no 1.995/12, que dispõe sobre as diretivas antecipadas de vontade para o final da vida (2012); Políticas públicas como a de Humanização (2004) e da Atenção Oncológica (2005); a implementação de programas como o Melhor em Casa (2010), e o fortalecimento de instituições que emitem verdades sobre os Cuidados 
Paliativos no Brasil, como a Academia Nacional dos Cuidados Paliativos (ANCP). Junto a isso, as revistas apontam que morrer bem é morrer em casa. Ensinam que a morte no domicílio é a boa morte, que ali pessoas morrem 'felizes e cheias de vida', como demonstra o excerto abaixo.

Um dos meus maiores pesadelos é ter de ficar internada. No hospital, só vejo morrer gente na mesma situação que eu. Como meu caso não tem mais solução, é melhor ficar em casa, que é um lugar cheio de criança e vida. (paciente fora de possibilidade terapêutica) ${ }^{17}$ (p. 95)

Busca-se a qualidade de vida e o afastamento daquilo que lembre o fim, a começar pelos ambientes, como o hospital, especialmente os que não possuem espaços de cuidados paliativos. Apesar do discurso da boa morte no domicílio ser interessante, positivo e produtivo, acreditamos que muitas das famílias brasileiras não possuem estrutura para abrigar e cuidar de pessoas doentes em condições de degradação física e emocional. Pessoas nessas condições exigem elevadas demandas de cuidado. O modelo que se propõe, inspirado nos padrões europeus para o final da vida, não encontra, em nosso país, as mesmas condições econômicas e estruturais para promover uma volta ao lar, resultando em danos aos envolvidos, especialmente aquele que vai morrer ${ }^{24}$. Esses danos podem estar relacionados a aspectos clínicos da doença, com os quais a família pode não ter estrutura ou capacitação para lidar, resultando na exacerbação de sintomas comuns em doenças que ameaçam a vida, como: a dor, a fadiga, a caquexia, entre outros. Também se destacam os danos à família, que pode sentir-se culpada por não saber lidar com o processo de morrer no domicílio.

O conceito da 'boa morte' está relacionado com a aceitação desse acontecimento e com a possibilidade de um morrer tranquilo e seguro, junto da família. Quando, nas revistas, fala-se que pessoas com melhores condições econômicas, culturais, aquelas que viveram mais felizes ou que conseguiram realizar seus objetivos, são as que têm maior capacidade de aceitação do fim, tratamos de um sujeito moldado pelas investidas de uma biopolítica neoliberal, de um sujeito que é considerado protagonista da sua vida e da sua morte.

Sob a lógica neoliberal, a ordem é a competição, em um mundo no qual é preciso, antes de competir com os demais, competir consigo, na busca incessante pelo melhor que se pode ser, pelo melhor trabalho que se pode ter, pela melhor roupa que se pode vestir ${ }^{25}$. Trata-se de um trabalho imaterial e virtual sobre si, no qual são exigidas alta capacidade de comunicação, tomada de decisão, criatividade e, sobretudo, gestão dos acontecimentos, do imprevisível e do previsível ${ }^{26}$. A produção desses sujeitos que governam suas vidas e suas mortes perpassa pela mídia, pelo Estado, pelos sistemas jurídico e médico, entre outros. Por meio de práticas institucionais, molda-se desde o modo como se nasce até ao modo como se morre. Nas reportagens, evidencia-se que depende de cada um aceitar e experimentar um bom final da vida. Esse é o padrão que vai desenhando a norma da 'boa morte'.

As pessoas são estimuladas a aceitar o sofrimento e a dor que o final da vida pode trazer, sendo incitadas a encararem a morte pensando na vida e no que ela tem de positivo. Sintomas como fadiga, fraqueza, hesitação, padecimento, característicos das doenças fora de possibilidade de cura, são suprimidos na tentativa de viver uma vida e uma morte permeadas pela felicidade, que é tanto compulsiva como compulsória ${ }^{27,28}$. Trata-se de um jeito diferente de nos constituírmos como sujeitos deste tempo, que nos individualiza e conduz à busca da felicidade. Esse imperativo se relaciona com o enunciado da individualização, pois indica como as pessoas em processo de morrer devem investir na felicidade para produzirem uma morte digna. A aceitação desse evento, atrelada ao imperativo da felicidade, assinala que a morte serena depende do investimento e do cuidado que cada um despende no final da sua vida. Trata-se de se reconhecer e constituir como sujeito de suas ações, que, em relação com o outro, define o que é melhor para si, diante de determinadas circunstâncias que rondam o fim ${ }^{29}$.

Nesse sentido, morrer bem depende de quanto cada um investe em si e, assim, proporciona-se uma boa morte. As revistas delegam, aos leitores, a responsabilidade dessa decisão, a partir daquilo que circulam. Aqueles que não aceitam o fim e decidem insistir na vida estão errados, pois provocam sofrimento e prolongam a morte, tida como indigna e sem qualidade. Para isso, recorre-se, novamente, à narrativa e à experiência de pessoas que tiveram a morte "adequada" ou a morte considerada 'anormal'. A revista Veja cita o exemplo positivo de Jacqueline Kennedy Onassis, que, após receber 
o diagnóstico de um Linfoma Não Hodgkin, decidiu não permanecer no hospital e elaborar um testamento vital, reforçando que não gostaria de morrer atrelada a aparelhos. Ela é indicada como um exemplo a ser seguido. A Veja também cita quanto a população estadunidense modificou sua forma de encarar o fim a partir do exemplo da ex-primeira-dama. A revista Época aponta o que acontece com os sujeitos que decidem insistir na vida, trazendo o exemplo da escritora Susan Sontag, que, mesmo tendo escrito livros sobre doença, sofrimento e morte, não conseguiu lidar com a própria terminalidade.

Em observância de seu testamento vital, Jacqueline Kennedy Onassis foi levada ao seu apartamento na quinta Avenida de Manhattan, quando nada mais podia ser feito para livrá-la de um câncer em estágio avançado. O caso de Jackie ajudou a popularizar o testamento em vida e, há três anos, 40\% dos americanos declaram ter assinado um desses documentos. ${ }^{22}$ ( $p$. 107)

A escritora Susan Sontag fez uma escolha oposta. Autora de livros sobre a doença e a morte, Susan morreu com câncer em 2004, aos 71 anos, sem conseguir aceitar sua condição [...]. Susan morreu coberta de feridas e hematomas, sem se despedir de ninguém. Seus últimos meses foram descritos pelo filho, David Rieff, em 'Nadando em um mar de morte- memórias de um filho'. 'Eu não podia nem dizer que a amava, porque isso seria interpretado como despedida', diz David. ${ }^{14}$ (p. 62)

Há uma dramatização e culpabilização daqueles que não conseguem se inserir na ordem do discurso da 'boa morte'. O sofrimento, aspecto tão temido por aqueles que estão no final da vida, assola os que decidem insistir nos tratamentos considerados inúteis ou fúteis. É preciso desistir de determinadas terapêuticas e da tecnologia, caso contrário, a solidão, a tristeza e a infelicidade estarão presentes durante o processo de morrer. Segundo os manuscritos, investir em terapêuticas tem como efeito o sofrimento, não somente daqueles que vão morrer, mas, também, 'prejudica' os envolvidos, que se angustiam por não participarem ativamente do conforto durante a morte de um familiar.

Por meio de exemplos, da linguagem e de uma pedagogia de valores, as revistas educam, ensinam e apontam o que é correto na hora do fim. Os discursos que elas fazem circular devem vir de pessoas conhecidas, na tentativa de legitimar o que circula. Cita-se a ex-primeira-dama dos Estados Unidos, uma nação apresentada como poderosa e desenvolvida, e uma autora de livros sobre doença e morte que ganhou reconhecimento e prestígio por suas produções no meio acadêmico. Com essa articulação entre as narrativas, as experiências e o status dos enunciadores, constroem-se as regras de circulação daquilo que se quer tornar verdade. O que se enuncia ganha força para a constituição de posições de sujeitos $^{12}$, as quais os leitores são chamados a ocupar.

\section{A avaliação das condutas de si e dos outros}

A partir da intervenção midiática, que põe em voga outras práticas sobre a morte contemporânea, somos aconselhados e orientados por discursos que "propõe a todos nós que façamos minuciosas operações sobre nosso corpo, sobre nossos modos de ser, sobre as atitudes a assumir"16 (p. 156). Trata-se de um governo de si pelo discurso do outro, que orienta e, depois do processo educativo, também avalia.

A avaliação faz parte do processo de aprendizagem e, nos currículos atuais, desempenha um papel fundamental. Por meio dela, é possível verificar quanto cada um aprendeu sobre aquilo que the foi ensinado, quanto ainda precisa estudar e quanto introjetou de um assunto para mudar aspectos de sua vida. Nas revistas, esse jogo avaliativo também entra em cena. Trazemos, como exemplo, um teste produzido pela revista Veja, que busca aferir se os sujeitos estão prontos para elaborarem o testamento vital (Figura 3). Esse documento foi apresentado na edição de setembro de 2012 e está articulado com: os conceitos de qualidade de vida, a inserção da família na hora e depois da morte, e as questões financeiras levantadas ao longo das reportagens. 


\begin{tabular}{|c|c|c|c|}
\hline \multicolumn{4}{|c|}{ 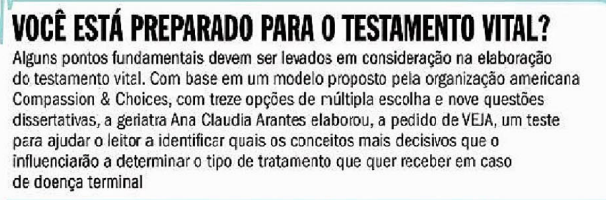 } \\
\hline \multicolumn{4}{|c|}{ ) 4} \\
\hline \multicolumn{3}{|c|}{ 1) Deixar a natureza seguir seu curso } & 01234 \\
\hline \multicolumn{3}{|c|}{$\begin{array}{l}\text { 2) Preservar minha qualidade de vida, ou seja, ser capaz } \\
\text { de fazer e viver tudo aquilo que considero importante }\end{array}$} & 01234 \\
\hline \multicolumn{3}{|c|}{ 3) Manter-me fiel às minhas crenças espirituais e tradiçōes } & 012234 \\
\hline \multicolumn{3}{|c|}{$\begin{array}{l}\text { prolongada se não for possivel manter } \\
\text { de vida }\end{array}$} & 012334 \\
\hline \multicolumn{3}{|c|}{$\begin{array}{l}\text { 5) Ser capaz de tomar minhas próprias decisōes e ser } \\
\text { independente para poder vijjar, trabalhar e sair com os amigos }\end{array}$} & 01234 \\
\hline \multicolumn{3}{|c|}{$\begin{array}{l}\text { 6) Sentir-me confortável, com o mínimo de sofrimento } \\
\text { físico possível }\end{array}$} & 01234 \\
\hline \multicolumn{3}{|c|}{ 7) Poupar a minha familia de me ver doente } & 012234 \\
\hline \multicolumn{3}{|c|}{$\begin{array}{l}\text { 8) Ser capaz de me relacionar com meus } \\
\text { tamiliares e amigos }\end{array}$} & 01234 \\
\hline \multicolumn{3}{|c|}{$\begin{array}{l}\text { 9) Estar livre de limitaçóes físicas que me impeçam } \\
\text { de cuidar de mim mesmo }\end{array}$} & 01234 \\
\hline \multicolumn{3}{|c|}{ 10) Estar consciente e dono de minhas faculdades mentais } & 01234 \\
\hline \multicolumn{3}{|c|}{$\begin{array}{l}\text { 11) Morrer rapidamente e nào ter a vida } \\
\text { prolongada de modo artificial }\end{array}$} & 01234 \\
\hline \multicolumn{3}{|c|}{$\begin{array}{l}\text { 12) Näo gastar muito dinheiro com assistência médica no fim } \\
\text { da minha vida para evitar prejuizos finarceiros à familia }\end{array}$} & 01234 \\
\hline \multicolumn{4}{|c|}{$\begin{array}{l}\text { Ftaja } 2 \text { Some os pontos de cada uma das doze questôes } \\
\text { e confira o resultado abaixo }\end{array}$} \\
\hline $\begin{array}{l}\text { Até } 15 \text { pontos } \\
\text { Você prefere ser submetido a } \\
\text { todas as opçaes terapeutticas } \\
\text { para prolongar sua existencia, } \\
\text { mesmo que isso custe caro } \mathrm{e} \\
\text { que não haja a possibilidade } \\
\text { real de manter-se com boa } \\
\text { qualidade de vida }\end{array}$ & $\begin{array}{l}\text { De } 16 \text { a } 32 \text { pontos } \\
\text { Você ainda não se } \\
\text { sente preparado } \\
\text { oara decidir sobre } \\
\text { como prefere morrer } \\
\text { caso seja acometido } \\
\text { por uma doença } \\
\text { eerminal }\end{array}$ & \multicolumn{2}{|c|}{$\begin{array}{l}\text { De } 33 \text { a } 48 \text { pontos } \\
\text { Você quer ter sua vontade } \\
\text { respeetada com base nas } \\
\text { condiçōes que estabeleceu } \\
\text { para si mesmo, sem } \\
\text { o prolongamento } \\
\text { desnecessário (e artificial) } \\
\text { de sua vida }\end{array}$} \\
\hline
\end{tabular}

Figura 3. Quiz do testamento vital.

Fonte: Veja ${ }^{15}$.

A Figura 3 mostra um tipo de avaliação encontrado com frequência nas revistas. Geralmente, elas utilizam questionários do tipo quiz(d) para identificar o nível de aprendizagem dos leitores sobre um assunto. Nesse instrumento, quem realiza o teste deve estar apto a mudar, para que possa estar inserido na norma da aceitação da morte. Espera-se que o leitor reveja seus valores e analise suas práticas a fim de inserir-se no grupo daqueles que estão abertos às mudanças, que são flexíveis conforme aquilo que se apresenta como correto no momento ${ }^{30}$.

Verificamos o direcionamento das respostas para a escolha dos elementos apontados como favoráveis para se obter um bom final de vida. Deixar a doença tomar o curso natural, pensar nas finanças da família e na qualidade de vida que se pode ter nesse momento são fatores elencados na hora de tomar a decisão correta. Notamos que o questionário foi elaborado a partir das orientações de uma médica entrevistada em outras reportagens das revistas, seguindo os moldes de uma organização estadunidense que auxilia pessoas a elaborarem testamentos vitais e cometerem suicídio assistido, e oferece orientações espirituais, entre outros serviços. A opção por trazer sujeitos e instituições que tenham visibilidade assegura a validade do teste que se aplica aos leitores. Esse papel avaliativo, que indiretamente é realizado por experts e operado pelas revistas, consolida e efetiva o papel da mídia como um dispositivo pedagógico que não apenas ensina,

\author{
(d) Quizzes são \\ questionários \\ utilizados para avaliar \\ quantitativamente \\ quanto uma pessoa sabe \\ sobre algum assunto. \\ Geralmente, são objetivos \\ e fechados, possibilitando \\ respostas do tipo sim \\ ou não. Muitas revistas \\ utilizam esse instrumento \\ como uma ferramenta \\ avaliativa dos leitores, no \\ final de algum assunto \\ abordado. Além de \\ aferirem a capacidade \\ de absorção de um \\ conteúdo, eles também \\ funcionam como um \\ elemento interativo entre \\ o leitor e a revista.
}


mas que, também, avalia e julga aqueles que ela categoriza como os "não preparados" para morrer. Essas avaliações também contribuem para debater aquilo que é difundido e se torna 'o tema da vez'. As ferramentas avaliativas proporcionam a interação do leitor com os meios de comunicação, dandoIhes um caráter atual, tornando seu consumo atrativo e ajudando a disseminar e fixar as ideias que veiculam ${ }^{12}$.

Essas ferramentas se configuram como uma das táticas que favorecem o governo, não só da vida, como também da morte, visto que elas "operam no nível da população: dividindo, ordenando, indexando, ranqueando, julgando"21 (p. 11). As regularidades produzidas pelas políticas de saúde, resoluções e diretrizes são postas em circulação pela mídia, possibilitando conhecer, planejar e intervir nas condutas das pessoas em processo de morrer. Com isso, é possível moldar o comportamento dos indivíduos, otimizando as práticas de governo sobre os corpos, que delimitam as fronteiras de atuação dos profissionais sobre os doentes, do Estado sobre as coletividades e da constituição de cada um a partir dos discursos que atravessam essas disposições em torno da morte contemporânea.

\section{Algumas considerações para (não) finalizar}

A mídia produz o currículo do final da vida. Ela educa e mostra o caminho correto para aquilo que parece ser a ordem do discurso atual: a 'boa morte' como sinônimo de aceitação desse acontecimento. Por meio da disposição das imagens, dos jogos com as luzes, das cores, dos quadros e dos números, inventa-se o caráter legítimo e verdadeiro para aquilo que se quer pôr no jogo político sobre o morrer. A partir dessas disposições, os sujeitos podem ser capturados e subjetivados pelo modelo que as revistas veiculam. Pouco a pouco, elas nos ditam as formas como devemos morrer nos dias atuais, articulando ciência, mídia, cotidiano de vida e justiça, convidando os sujeitos a participarem das diferentes táticas para a (re)domesticação, a legitimação e a docilização da morte, nos moldes da racionalidade neoliberal.

Hoje, a aceitação da morte talvez seja um enunciado que desponta de forma mais imperativa. Somos atravessados por esse enunciado que nos constitui como sujeitos que querem decidir o seu fim. Sujeitos que querem ter uma boa morte, evitando medidas fúteis quando viver já não é mais possível. Decidir sobre o fim é uma ação modulada pelos diferentes dispositivos que nos ensinam a produzir esse outro jeito de morrer. Talvez a mídia seja um dos importantes articuladores para efetivar novas práticas e fazeres sobre a morte no contemporâneo.

\section{Colaboradores}

Franciele Roberta Cordeiro e Maria Henriqueta Luce Kruse trabalharam juntas em todas as etapas de elaboração do manuscrito. 


\section{Referências}

1. Veiga-Neto A. Currículo: um desvio a direita ou delírios avaliatórios [Internet]. In: Mendonça A, organizador. Anais do X Colóquio sobre questões curriculares e VI Colóquio Luso-Brasileiro de currículo; 2012 [acesso 2013 Dez 20]. Disponível em: http://www. fe.unicamp.br/TEMPORARIOS/veiga-neto-curriculos-delirios-avaliatorios.pdf

2. Santaella L. Culturas e artes do pós-humano: da cultura das mídias à cibercultura. São Paulo: Paulus; 2003.

3. Hennigen I, Guareschi NMF. A subjetivação na perspectiva dos estudos culturais e foucaultianos. Psicol Educ. 2006; 23(2):57-74.

4. Ohnsorge K, Keller HRG, Widdershoven GA, Rehmann-Sutter C. 'Ambivalence' at the end of life: how to understand patients' wishes ethically. Nurs Ethics. 2012; 19(5):629-41.

5. Larrosa J. Notas sobre a experiência e o saber da experiência. Rev Bras Educ. 2002; 19(3):20-8.

6. Rehmann-Sutter C, Hagger L. Organised assistance to suicide in England? Health Care Anal. 2013; 21(2):85-104.

7. Leonetti J. Rapport fait: au nom de la mission d'information sur l'accompagnement de la fin de vie. Assemblee Nationale de France. 2004; 9-300.

8. Conselho Federal de Medicina. Resolução no 1.995 de 09 de agosto de 2012. Dispõe sobre as diretivas antecipadas de vontade dos pacientes. Diário Oficial da União. 9 Ago 2012.

9. Hall S. A centralidade da cultura: notas sobre as revoluções culturais do nosso tempo. Educ Real. 1997; 22(2):15-46.

10. Cordeiro FR. Eu decido meu fim: a mídia e a produção de sujeitos que governam sua morte [dissertação]. Porto Alegre (RS): Universidade Federal do Rio Grande do Sul; 2013.

11. Muhr T. Atlas.ti: qualitative data analysis, version 7. Berlim; 2013.

12. Foucault M. A arqueologia do saber. 7a ed. Rio de Janeiro: Forense Universitária; 2008.

13. Foucault M. A ordem do discurso. 7a ed. São Paulo: Loyola; 2003.

14. A mulher que alimentava. Época [Internet]. 2008 [acesso 2013 Jan 15]. Disponível em: http://revistaepoca.globo.com/Revista/Epoca/0,,EMI10410-15257,00A+MULHER+QUE+ALIMENTAVA.html

15. Lopes AD, Cuminale N. O direito de escolher. Veja [Internet]. 2012 [acesso 2013 Jan 12]; 45(37):98-106. Disponível em: http: //veja.abril.com.br/acervodigital/home.aspx

16. Fischer RMB. The media pedagogical apparatus: ways of educating on (and through) TV. Educ Pesqui. 2002; 28(1):151-62.

17. Corrêa R. Em busca de um final sereno. Veja [Internet]. 2005 [acesso 2013 Jan 12]; 38(45):92-100. Disponível em: http: //veja.abril.com.br/acervodigital/home.aspx

18. Sibilia P. O show do eu: a intimidade como espetáculo. Rio de Janeiro: Nova Fronteira; 2008.

19. Fischer RMB. Adolescência em discurso: mídia e produção de subjetividade [tese]. Porto Alegre (RS): Universidade Federal do Rio Grande do Sul; 1996.

20. Charaudeau P. Discurso das mídias. São Paulo: Contexto; 2009.

21. Rocha CMF. A escola na mídia: nada fora do controle [tese]. Porto Alegre (RS): Universidade Federal do Rio Grande do Sul; 2005.

22. Lopes AD. A ética na vida e na morte. Veja [Internet]. 2010 [acesso 2013 Jan 12]; 43(17):100-8. Disponível em: http: //veja.abril.com.br/acervodigital/home.aspx 
23. Foucault M. Segurança, território e população: curso no Collège de France: 1977-1978. São Paulo: Martins Fontes; 2008.

24. Menezes R. Em busca da 'boa morte': uma investigação sócio-antropológica sobre cuidados paliativos [tese]. Rio de Janeiro (RJ): Universidade Federal do Rio de Janeiro; 2004.

25. Foucault M. Nascimento da biopolítica. 3a ed. São Paulo: Martins Fontes; 2008.

26. Lazzarato M. As revoluções do capitalismo. Rio de Janeiro: Record; 2006.

27. Castro G. Para repensar a felicidade nos dias atuais. Comun Midia Consumo. 2011; 7(20):343-5.

28. Freire Filho J. Ser feliz hoje: reflexões sobre o imperativo da felicidade. Rio de Janeiro: Fundação Getúlio Vargas; 2010.

29. Foucault M. História da sexualidade: o cuidado de si. 9a ed. Rio de Janeiro: Graal; 2007.

30. Gerzson VRS. A mídia como dispositivo da governamentalidade neoliberal: os discursos sobre educação nas revistas Veja, Época e Isto é [tese]. Porto Alegre (RS): Universidade Federal do Rio Grande do Sul; 2007.

Cordeiro FR, Kruse MHL. La producción del currículo del final de la vida por medio del dispositivo pedagógico de los medios. Interface (Botucatu). 2015; 19(55):1193-205.

En este artículo, que partió de una investigación documental cuyo referente teóricometodológico fue el pensamiento de Michael Foucault, se analiza como los discursos sobre la muerte circulan en los medios brasileños, produciendo un currículo del final de la vida. El material empírico constó de diez reportajes que circularon entre 2002 y 2012 en las revistas Época y Veja. Para delimitar el corpus de análisis se elaboró un mapeo discursivo con el software ATLAS.ti 7, y los hallazgos se sometieron al análisis del discurso de inspiración foucaultiana. La aceptación de la muerte y su domesticación surgen como estrategias producidas por el Estado y legitimadas por los medios. Las revistas informativas brasileñas producen un currículo del final de la vida, enseñando y propagando la aceptación de la muerte y convocando a los sujetos para que gobiernen su fin. Aquellos que están fuera de ese orden discursivo se consideran "anormales" en el contexto del final de la vida.

Palabras clave: Muerte. Enfermería. Medios. Educación en enfermería. Estudios culturales.

Recebido em 24/09/14. Aprovado em 02/01/15. 
